\title{
Trimodality therapy for esophageal squamous cell carcinoma: Is it really a medical palindrome?
}

\author{
Usman Ahmad, MD, Sudish C. Murthy, MD, PhD, and Siva Raja, MD, PhD
}

\author{
From the Department of Cardiothoracic Surgery, Section of Thoracic Surgery, Heart and Vascular Institute, \\ Cleveland Clinic, Cleveland, Ohio. \\ Disclosures: Authors have nothing to disclose with regard to commercial support. \\ Received for publication March 24, 2017; accepted for publication March 24, 2017; available ahead of print May \\ 23, 2017. \\ Address for reprints: Siva Raja, MD, PhD, Department of Cardiothoracic Surgery, Heart and Vascular Institute, \\ Cleveland Clinic, Cleveland, OH 44195 (E-mail: rajas@ ccf.org). \\ J Thorac Cardiovasc Surg 2017;154:741-2 \\ $0022-5223 / \$ 36.00$ \\ Copyright (c) 2017 by The American Association for Thoracic Surgery \\ http://dx.doi.org/10.1016/j.jtcvs.2017.03.107
}

We like to think that there is a perfect order for everything. In a restaurant, we order the appetizer, then the entrée, and then the dessert. Straightforward and easy to remember! But why must the simple, hierarchic ordering system become so inconsistent and impossible to remember when it comes to the management of locally advanced esophageal squamous cell cancer (ESCC)?

The treatment of locally advanced resectable esophageal cancer has been the subject of longstanding debate. Although clinical trials have confirmed the efficacy of trimodality treatment (chemotherapy, radiation, and resection), ${ }^{1,2}$ specifics of the timeline for the treatment regimens remain far from settled.

In this issue of the Journal, Hsu and colleagues ${ }^{3}$ have tried to address the question of neoadjuvant versus adjuvant chemotherapy and radiotherapy (chemoRT) in resectable ESCC. Hsu and colleagues ${ }^{3}$ performed a retrospective review of the Taiwan Cancer Registry and identified patients with clinical stage II or III ESCC who underwent trimodality treatment with either neoadjuvant or adjuvant chemoRT. The cohorts were propensity matched for age, sex, and cancer characteristics. The adjuvant chemoRT group had a higher proportion of patients with incomplete resections than the neoadjuvant group (23\% vs $10 \%)$, similar overall survival $(38 \%$ vs $44 \%)$, and similar disease-free survival (30\% vs $38 \%$ ). Despite the statistical nonsignificance, there was a trend toward improved disease-free survival and overall survival with neoadjuvant chemoRT. These findings add some support to the notion that both neoadjuvant and adjuvant therapy can result in comparable survival and therefore both have value in the management of ESCC.

With big data from big databases we expect big results, but they also often come with big gaps. In this retrospective study, the role of selection bias in choosing sequence of treatment cannot be accounted for. Similarly, propensity matching without comorbidity data in the propensitymatching algorithm may be a source of selection bias. Assuming truly well-matched comparison groups, the trend

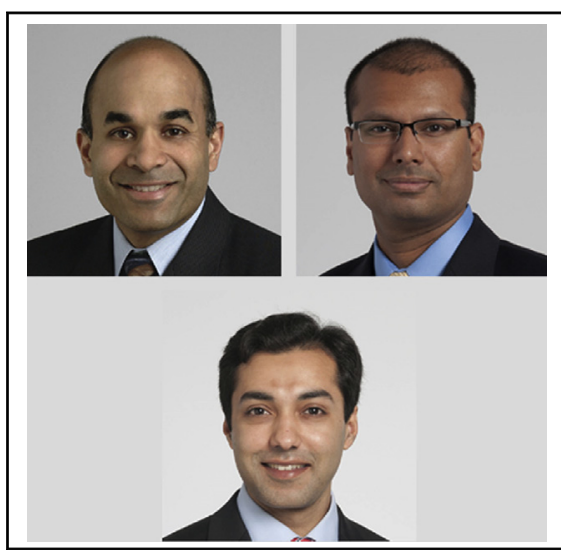

Sudish C. Murthy, MD, PhD (leff), Siva Raja, MD, PhD (right), and Usman Ahmad, MD (bottom)

\section{Central Message}

Trimodality therapy is the standard of care for locally advanced esophageal cancer. Although the order of treatment regimens is somewhat controversial, a consensus is starting to emerge.

See Article page 732 .

toward greater overall and disease-free survivals, along with the higher rate of complete resection, favors the choice of neoadjuvant treatment.

With the completion and publication of the landmark Chemoradiotherapy for Oesophageal Cancer Followed by Surgery Study, ${ }^{1}$ which demonstrated a value to neoadjuvant chemoRT, it would be difficult to propose and conduct a randomized study evaluating the question examined in this retrospective analysis. In fact, most clinicians (ourselves included) do not have the clinical equipoise to participate in such a study in which resection is the first modality used in these locally advanced cancers. In addition, there is level 1 evidence in other thoracic malignancies suggesting that patients are more likely to complete the systemic component of treatment in the neoadjuvant setting than in the adjuvant setting. ${ }^{4}$

Adjuvant chemoRT for locally advanced esophageal cancer can provide similar results in a subset of patients and should be considered for patients who have their disease upstaged to pathologic stage II or III. For patients with clinical stage II or III disease, however, neoadjuvant chemoRT followed by resection remains the treatment of choice. If you are still not satisfied, the next time you visit 
a fine dining establishment, try ordering the dessert first and the appetizer last. Let us know if the food tastes any different....

\section{References}

1. van Hagen P, Hulshof MC, van Lanschot JJ, Steyerberg EW, van Berge Henegouwen MI, Wijnhoven BP, et al; CROSS Group. Preoperative chemoradiotherapy for esophageal or junctional cancer. $N$ Engl J Med. 2012;366:2074-84.
2. Walsh TN, Noonan N, Hollywood D, Kelly A, Keeling N, Hennessey TP. A comparison of multimodal therapy and surgery for esophageal adenocarcinoma. N Engl J Med. 1996;335:462-7.

3. Hsu PK, Chen HS, Liu CC, Huang CS, Hsieh CC, Hsu HS, et al. Pre- versus postoperative chemoradiotherapy for locally advanced esophageal squamous cell carcinoma. J Thorac Cardiovasc Surg. 2017:154:732-40.

4. Felip E, Rosell R, Maestre JA, Rodríguez-Paniagua JM, Morán T, Astudillo J, et al; Spanish Lung Cancer Group. Preoperative chemotherapy plus surgery versus surgery plus adjuvant chemotherapy versus surgery alone in early-stage non-small-cell lung cancer. J Clin Oncol. 2010;28:3138-45. 